\title{
Valuing the impacts of an invasive biological control agent: a choice experiment on the Asian ladybird in France
}

\author{
Raja Chakir, Maia David, Estelle Gozlan and Aminata Sangare*
}

June 30, 2015

\begin{abstract}
Initially used as a biological control agent against Aphids, the Asian ladybird has become highly invasive in many regions, including Europe. While biological control is usually considered as an environmentally-friendly alternative to chemical pesticides in controlling pests in crops, there is growing concern that these environmental benefits could be outweighed by the negative consequences of the invasion. These include (i) biodiversity losses as populations of native ladybirds suffer from intraguild predation and competition for resources; (ii) human nuisance in houses, including risks of allergy and (iii) potential losses to wine-growers. The aim of this paper is to provide an economic valuation of environmental and private characteristics affected by the Asian ladybird's invasion. We conduct a discrete choice experiment among a representative sample of the French population. Our results show that the consequences of the Asian ladybird's introduction do affect significantly the population's welfare. Among these, the impact on biodiversity through the threat on native species appears to be a significant concern. The tradeoffs elicited suggest that people are willing to accept a small increase in pesticides to preserve native ladybirds.
\end{abstract}

Keywords: Non-market valuation; Discrete choice experiment; Biological Invasion; Biological Control; Biodiversity; Pesticides.

JEL Classification: Q10, Q51, Q57, C35

${ }^{*}$ UMR Economie Publique, INRA-AgroParisTech, BP01, 78850 Thiverval-Grignon, France. Tel: $33(0) 130$ 8153 37. E-mail: raja.chakir@grignon.inra.fr; maia.david@agroparistech.fr; esgozlan@grignon.inra.fr. We wish to thank Jens Abildtrup, Elodie Brahic, Jeanne Dachary-Bernard, Arnaud Estoup, Bérénice Fassote, Marc Kenis, Eric Lucas, Jayson Lusk, Bénédicte Rulleau, Axel Vandereycken, and all the participants of our focus group for help and useful comments. This project is supported by Agropolis Fondation under the reference ID 1001-001. 


\section{Introduction}

Biological control is usually considered as an efficient and environmentally-friendly method of pest management. Its advocates indicate that biological control outperforms chemical control on many aspects: specificity, success ratio, benefit/cost ratio and less harmful side effects van Lenteren, 2012). In particular, in comparison to chemical insecticides, biological control avoids the release of toxic substances harming non-targeted species (including humans) and avoids the development of resistance in targeted pests. Public concern about chemical pesticides has grown dramatically over the last decades with mounting evidence of their health and ecological effects. Recent studies suggest that citizens in developed countries have a positive willingness to pay (WTP) to avoid exposure to pesticides (see for example Florax et al. (2005) for a meta-analysis).

However, adverse non-target effects of biological control have been observed in a number of situations. These include the release and spread of exotic species that have become invasive. Invasive species are considered as a major environmental concern and represent one of the top drivers of global biodiversity loss (ISSG, 2000). Even though there is general agreement that sound risk assessment procedures should precede the release of exotic invertebrate biological control agents, there is no consensus on how to judge the magnitude of non-target effects and whether these effects could outweigh the benefits of biological control (De Clercq et al., 2011).

Our study aims at providing some economic insights in this debate. In particular, we value individual preferences with regard to some of the costs and benefits associated with the use of the Asian ladybird as a biological control agent and with the consequences of its invasion.

Section 2 presents the background, recalling the reasons for the release of the Asian ladybird in Europe, highlighting the main problems associated with its spread, and discussing the possible options to mitigate these impacts (2.1); it also provides a quick survey of the economic non-market valuation literature addressing similar issues and highlights our original contribution (2.2). Section 3 focuses on the methodology we used to conduct our study. Results are presented in section 4 and discussed in section 5 .

\section{Background and insights from the literature}

\subsection{A tale of a good insect that has become a problem}

The Asian ladybird (Harmonia axyridis, see Figure 1) is an aphid predator that was voluntarily released in Europe in the 1990s as a biological control agent because of its voracity. It has been effective at controlling pest insects in a variety of crop systems. For reasons which remain unknown, it recently suddenly became highly invasive on four continents, including Europe 
where it has spread at the rate of approximately $200 \mathrm{~km} / \mathrm{yr}$ (Brown et al., 2008, 2011). For France, the following maps (Figure 2) illustrate the progression of the invasion between 2004 and 2011.

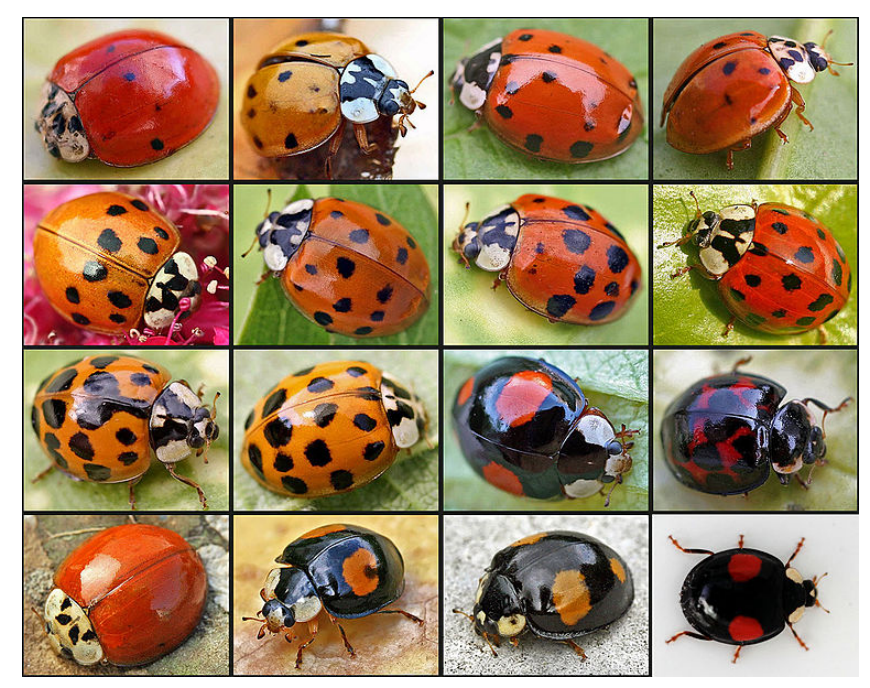

Figure 1: The multicolored Asian ladybird (Harmonia axyridis)

The Asian ladybird is now considered as one of the world's most invasive insects (Roy et al. 2006). The negative consequences of the invasion include:

- Biodiversity losses as populations of native ladybirds and other aphidophagous insects suffer from intraguild predation and competition for resources. According to a recent study for England, Belgium and Switzerland (Roy et al., 2012): "the decline in the distribution and abundance of previously widespread and common native ladybirds after the arrival of H. axyridis is striking. The dramatic decline of the European two-spot ladybird Adalia bipunctata [see picture on Figure 3 a.] over the five years following the arrival of $H$. axyridis is of particular note", with a decrease in native populations ranging from $30 \%$ (Belgium) to 45\% (England) and even 99\% (Switzerland). Brown et al. (2015) provide recent evidence of the predation on native species by the Asian ladybird in France, England, Slovakia and the Czech Republic;

- Human nuisance because the beetle aggregates in buildings when seeking overwintering sites in the autumn, thousands being reported in a single household (CABI Invasive Species Compendium). Human nuisances that have been reported include aesthetic inconvenience due to aggregates in the housing (see Figure 3 c.). Moreover, reflex bleeding ladybirds may stain furnishings and walls and result in unpleasant odors. Also, exposure to reflex blood may in some cases trigger allergic reactions in sensitive persons (Majerus et al. 2006; Koch and Galvan, 2008); 

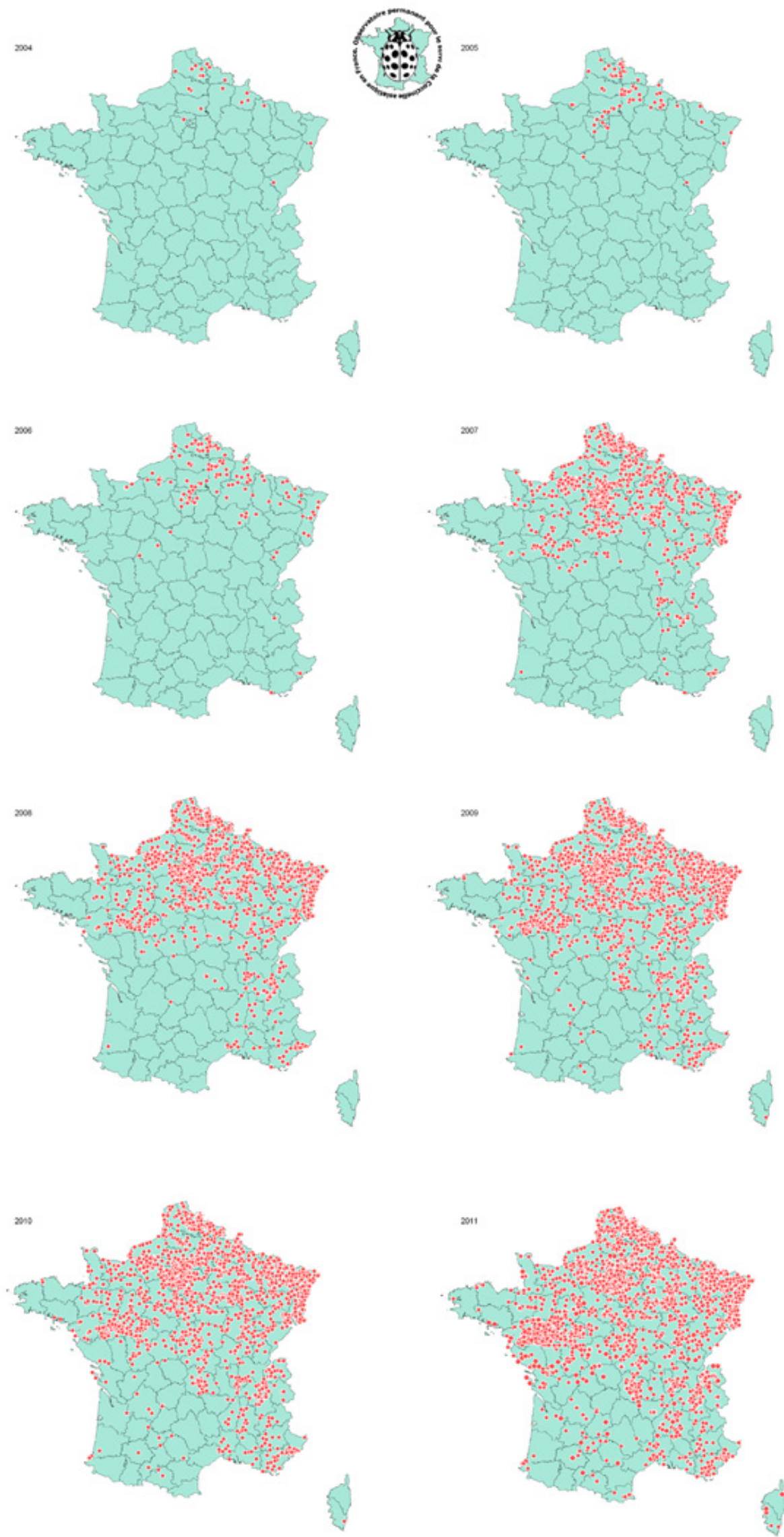

4

Figure 2: Invasion of the Asian ladybird in France 2004-2011 (Source: Observatoire Permanent

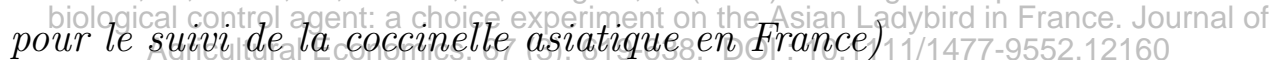


- Potential losses to wine-growers (Figure 3 b.), because the taste of wine can be spoiled when beetles are crushed with grapes (Pickering et al. 2004). This impact has been reported in North America 1 where the invasion of $H$. axyridis is also a concern, and to a lesser extent in Europe, including France.

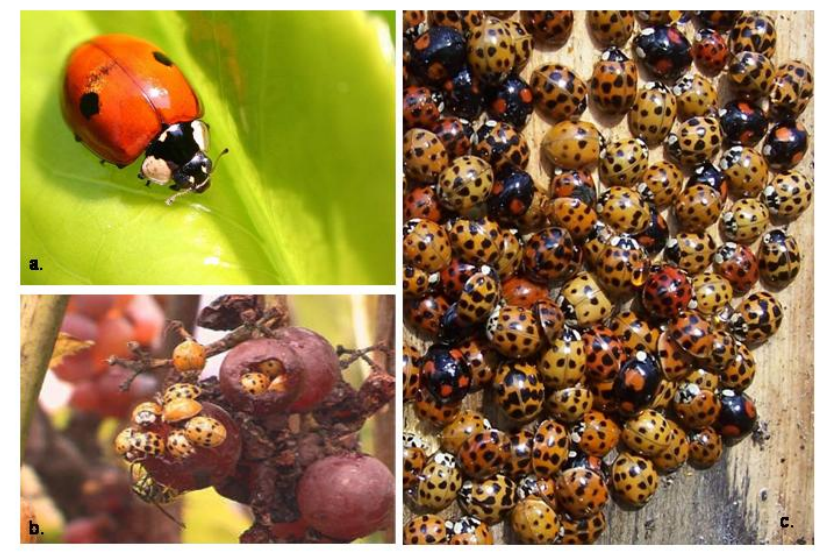

Figure 3: a. The threatened native species Adalia bipunctata ; b. Asian ladybird nuisance in vineyards; c. Asian ladybird aggregate in housing

Altogether, the negative consequences of the invasion have tarnished the image of a species that used to be a symbol of the "good beetle". Could these impacts be mitigated by public intervention or private actions ? Kenis et al. (2008) have surveyed current and potential management strategies against $H$. axyridis. These include mechanical control, trapping, chemical control, the use of deterrents, and even biological control. Some of the presented methods could solve the problems caused by beetles aggregating in houses and vineyards, while research needs to be pursued regarding methods to lower population densities in natural environments and to limit the impact of the Asian ladybird on native species 2 .

Pursuing research has a cost and economic questions arise. Should public money be spent to search and implement solutions to address the negative consequences of the invasion of the Asian ladybird? If so, what is the approximate budget that should be allocated? Since the impacts of the invasion are multiple and have both a private and a public good dimension, what are the priorities for public action? More generally, was the introduction of this insect as a biocontrol agent economically sound, i.e. do benefits overweight the costs? Should we

\footnotetext{
${ }^{1}$ In 2003, over a million litres of Harmonia-tainted wine had to be destroyed in Ontario, Canada (Ejbich, 2003).

${ }^{2}$ Among ongoing research, a sexually transmitted mite inducing host sterility could be a promising candidate for lowering the populations of $H$. axyridis (Rhule et al. 2010). Understanding the reasons why the native ladybird populations seem to be less declining in some countries (Germany) could also be of interest.
} 
consider its introduction in other regions 3 ?

The result of van Lenteren et al. (2008)'s environmental risk assessment stated that "in the H. axyridis case, current knowledge would lead to the conclusion that, although the predator is capable to effectively control several pest species (a strong benefit), its risks are manifold (...), and it should, thus, not have been released in Northwest Europe". However, this conclusion relies on the assumption that the costs that the invasion has put on our societies outweigh the benefits - while such a conclusion cannot be reached without an economic valuation of these costs and benefits. In particular, if the disappearance of native ladybirds does not matter to the citizens (either because they don't care about ladybirds, or because the Asian ladybird is considered a close substitute), and if the nuisances do not affect their utility significantly, while the use of pesticides does, then the conclusion of a cost-benefit analysis could be in contradiction to that of the environmental risk assessment.

An economic analysis of the use of the Asian ladybird is thus needed. By trying to elicit public preferences with regard to some of the consequences of the release of the Asian ladybird in France, providing willingness to pay estimates and highlighting tradeoffs, this article brings an original quantified contribution in this debate.

\subsection{Insights from the non-market valuation literature}

We wish to value, in monetary terms, the weight the French population grants to the positive and negative impacts of the Asian ladybird (reduction of pesticides, threat on native species, ...). Several non-market valuation methods are used in the literature to estimate the monetary value associated with environmental services or damages (stated preference methods and revealed preference methods).

In recent years, there has been an increasing use of choice experiments (also named discrete choice experiments, DCE) in non-market valuation (see Hoyos (2010) for a survey). Like other stated preference methods such as contingent valuation, this method captures the non-use value of environmental goods (existence value, bequest value...), which is useful when valuing endangered species or biodiversity. Moreover, it reveals more detailed information than a contingent valuation by yielding the willingness to pay for different aspects (i.e. attributes) of an environmental issue. On the other hand, its main disadvantage is that the survey is generally heavier than for other valuation methods, which may induce some cognitive difficulties (Hanley et al., 2002) and more complex econometric estimations.

\footnotetext{
${ }^{3}$ For example, Pervez and Omkar (2006) argued in 2006 that H. axyridis's "field releases in tropical countries like India should be encouraged; however, only after a thorough analysis of the cost and benefit of beneficial and non-target fauna". Nowadays, it seems highly debatable that new introductions of this insect should be encouraged given its invasive character.
} Agricultural Economics, 67 (3), 619-638. DOI : 10.1111/1477-9552.12160 
Although there are numerous contingent valuations dedicated to endangered species (see Richardson and Loomis (2009) for a meta-analysis of 43 such studies), and several related to the consequences of invasive species (Nunes and van den Bergh, 2004, McIntosh et al., 2010) and the use of pesticides (see Florax et al. (2005) for a meta-analysis), there are only a few DCEs in these fields.

To the best of our knowledge, Travisi and Nijkamp (2008) and Chalak et al. (2008) are among the only DCEs directly dedicated to the valuation of the impacts of chemical pesticides $4^{4}$. Travisi and Nijkamp (2008) analyze the perception of pesticide risks in Italy, taking into account potential impacts on biodiversity, groundwater quality and human health. According to their results, biodiversity seems to be one of the main concerns related to pesticides. Chalak et al. (2008) have driven two DCEs in the UK: one on the use of pesticides in cereal production and the other on fruits and vegetables. Their study aims at disentangling the respective weight of environmental impacts and health impacts in the willingness to pay for a reduction in pesticides. In comparison with our work, the designs used in these two papers do not involve the same trade-off between biodiversity and pesticides, as biodiversity losses are a consequence of chemical pesticides use, while in our problem, a decline in biodiversity is driven by an alternative to chemical pesticides.

Hanley et al. (2003, 2010); Bartczak and Meyerhoff (2013) and Wallmo and Lew (2011) use DCEs to value endangered species and species preservation policies. The species studied in these articles are respectively birds, mammals and fish. Insect species do not seem to have been the object of DCEs up to now, when according to Richardson and Loomis (2009) the willingness to pay to preserve an endangered species depends crucially on the species' type.

Our work contributes to the literature in three main ways. First, we provide a first DCE estimation of the willingness to pay of the French population for a reduction of chemical pesticides, in a context where their use has become controversial in this country. Second, we obtain some first DCE estimates of the value of an endangered species of the insect type, namely the emblematic two-spot ladybird (A. bipunctata). These two contributions meet the need for local monetary values of environmental goods linked to biodiversity and ecosystemic services (see Chevassus-au Louis et al. (2009)). Third, we give valuable insights towards a first cost-benefit analysis of the introduction of the Asian ladybird. Such an economic analysis was crucially lacking according to the ecological literature on the topic (Pervez and Omkar, 2006).

\footnotetext{
${ }^{4}$ Other DCEs address topics linked to pesticides, such as Michaud et al. (2013) and Yue and Tong (2009), who examine, respectively, the willingness to pay for eco-labeled (non-food) and organic (food) agricultural products.
} 


\section{Methodology}

\subsection{Survey design and choice experiment}

A discrete choice experiment consists of six main steps: the choice of the relevant attributes and their levels; the experimental design which consists in selecting a satisfactory sub-set of all the possible combinations among the attributes' levels; the design of the questionnaire; the data collection; the econometric estimations; the interpretation of the results.

\subsubsection{The choice of the attributes and their levels}

In our survey, respondents were asked to indicate which situation they would prefer, in a fiveyears time, between three options including the status quo situation, that is the situation in five years if nothing is done. Each option was characterized by different levels of several attributes, including a monetary attribute.

A fundamental question when designing a DCE is whether to present the choice sets in a labeled or an unlabeled form. In DCEs, labeled alternatives typically allow to link environmental and economic outcomes (measured by the level of selected attributes) to a specific policy option. In unlabeled DCEs, each alternative is named generically (eg. A, B, C...) and respondents differentiate among the proposed alternatives only through the attributes and their levels. Both methods have been commonly used in the literature and have their strengths and weaknesses. In particular, while labeled alternatives may make the choice task more concrete for respondents, recent contributions found evidence that a proportion of respondents chose on the basis of the label only (Doherty et al., 2013), and that unlabeled DCEs may be more suitable to investigate tradeoffs between attributes (Bekker-Grob et al., 2010). Such tradeoffs appear to be important in our investigation as one of our aims is to highlight priorities for the future policies. We therefore opted for an unlabeled DCE. Our main aim is to infer from respondents' choices their monetary value associated with each attribute as a first step to design policy action.

Discussions were held with experts in ecology and non-market valuation methods in order to identify the most significant attributes and their levels, and to characterize the status quo in terms of our chosen attributes. With the same aim, a focus group was organized allowing informal discussions with non-expert people. The chosen attributes were:

1. The level of pesticides used in agriculture. Three levels were associated with this attribute: the business-as-usual level, i.e. level in five years if nothing is done (status quo), a $3 \%$ increase compared to the business-as-usual level, a $3 \%$ decrease compared to the businessas-usual leve 5 .

\footnotetext{
${ }^{5}$ Note that, in our case study, several factors can affect the level of pesticides: the use of ladybirds as a
} Agricultural Economics, 67 (3), 619-638. DOI : 10.1111/1477-9552.12160 
2. The state of the population of the two-spot ladybird A. bipunctata (the most threatened European native ladybird species), representing the impact of the invasion on biodiversity. Three levels were associated with this attribute: disappeared (status quo), rare and abundant.

3. The damages caused by the Asian ladybird to human beings, their housing and fruit cultures were grouped in a unique attribute. Three levels were associated with this attribute, in proportion to the affected human population: high (status quo, $15 \%$ of the population), moderate (5\% of the population) and insignificant ( $1 \%$ of the population).

4. The cost attribute was chosen as an increase of yearly local taxes, with three possible values: $€ 0$ (status quo), $€ 5$ and $€ 10$. Taxation was preferred to voluntary donations to avoid free-riding effects (Whitehead, 2006) and this payment vehicle did not seem to meet major objections during the focus group.

See the table below for a summary of the attributes and their levels. The status quo level is indicated by "SQ".

\begin{tabular}{lll}
\hline Attributes & Description & Levels \\
\hline Pesticides & Use of chemical pesticides in agriculture & Business-as-usual level (SQ); \\
& & Reduction $(-3 \%) ;$ Increase $(+3 \%)$ \\
Biodiversity & State of Adalia bipunctata's population & Disappeared (SQ); Rare; Abundant \\
Nuisance & Damages on humans, housing and wine & High $(15 \%$, SQ); Moderate (5\%); \\
& $(\%$ of the population affected) & Insignificant $(1 \%)$ \\
Monetary & Increase in yearly local taxes & $€ 0(\mathrm{SQ}) ; € 5 ; € 10$ \\
contribution & & \\
\hline
\end{tabular}

Table 1: Attributes and levels

\subsubsection{Experimental design}

Once the attributes and their levels were chosen, the next step was to choose which options (i.e. combinations of attributes' levels) to include in the questionnaire. With four attributes and three associated levels each, the full factorial range of combinations $\left(3^{4}\right)$ was too wide to collect the respondents' opinion on all of them. We selected a statistically optimal sub-set of biological control agent, the use of pesticides to control the Asian ladybird in vineyards, etc. The chosen levels were selected after the pre-test, because it appeared that (i) respondents needed some quantitative elements to make a decision, (ii) in our case, the variations in the use of chemical pesticides were not major at the country level. 
these combinations using a Bayesian D-optimal design. This is the aim of experimental design techniques (see Louviere et al. (2000) ) and the dedicated software ${ }^{6}$. There are different types of experimental designs. The orthogonal design is widely used in the literature and selects the choice sets that procure the maximal information without any a priori information on the population's preferences. The efficient design yields more information for a given number of choice sets but requires a priori values (priors) on the population's preferences. These priors can be issued from previous studies in the literature or pilot studies. The efficient design, although less common than the orthogonal given its requirements, is recognized as superior in the literature7.

As a first step, we implemented a pilot study on a sample of students based on an orthogonal design. This allowed us to obtain priors in order to implement an efficient design on a representative sample of the population. The pilot study was administered to 204 French students on an engineering school campus in the Paris area (AgroParisTech). The efficient design was then obtained resulting in 9 choice sets. Each choice set is composed of the status quo and two alternative scenarios, as shown in the example presented below (Figure 4 , translated from French), in which the pesticide attribute is labeled "Pesticides", the state of Adalia bipunctata's population attribute is labeled "Biodiversity", the attribute related to damages on humans is labeled "Nuisances" and the cost attribute is labeled "Cost".

\subsubsection{Data collection and presentation of the questionnaire}

The survey was administered online in May 2014 by a survey institute, yielding 503 answers from a representative sample by quota of gender, age, place of residence (urban/rural) and socioprofessional category of the French population. The questionnaire was designed to last less than 15 minutes. After a short introduction on the topic of the survey, some general questions were asked related to the respondent's environmental attitudes (consumption of organic products, past voluntary donations, etc.). A summary of our problem was then presented through a video and slides. The meaning and detailed definition of each attribute was explained, along with examples. The information provided to the participants also included (i) general information about biological vs. chemical control of pests in agriculture, (ii) details about the various consequences of the invasion of $H$. axyridis and (iii) information about conceivable measures that could be thought of to address these impacts within a five-years time. The survey was explained to be a preliminary step in order to assess the population's willingness to pay to address the consequences of the problem, and thus to inform on the appropriate budget to dedicate to this field.

\footnotetext{
${ }^{6}$ We used NGene which is a reference in this field.

${ }^{7}$ Given the priors, NGene has basic information on respondents' preferences which allows a more targeted design, yielding more information for a given number of choices.
} Agricultural Economics, 67 (3), 619-638. DOI : 10.1111/1477-9552.12160 


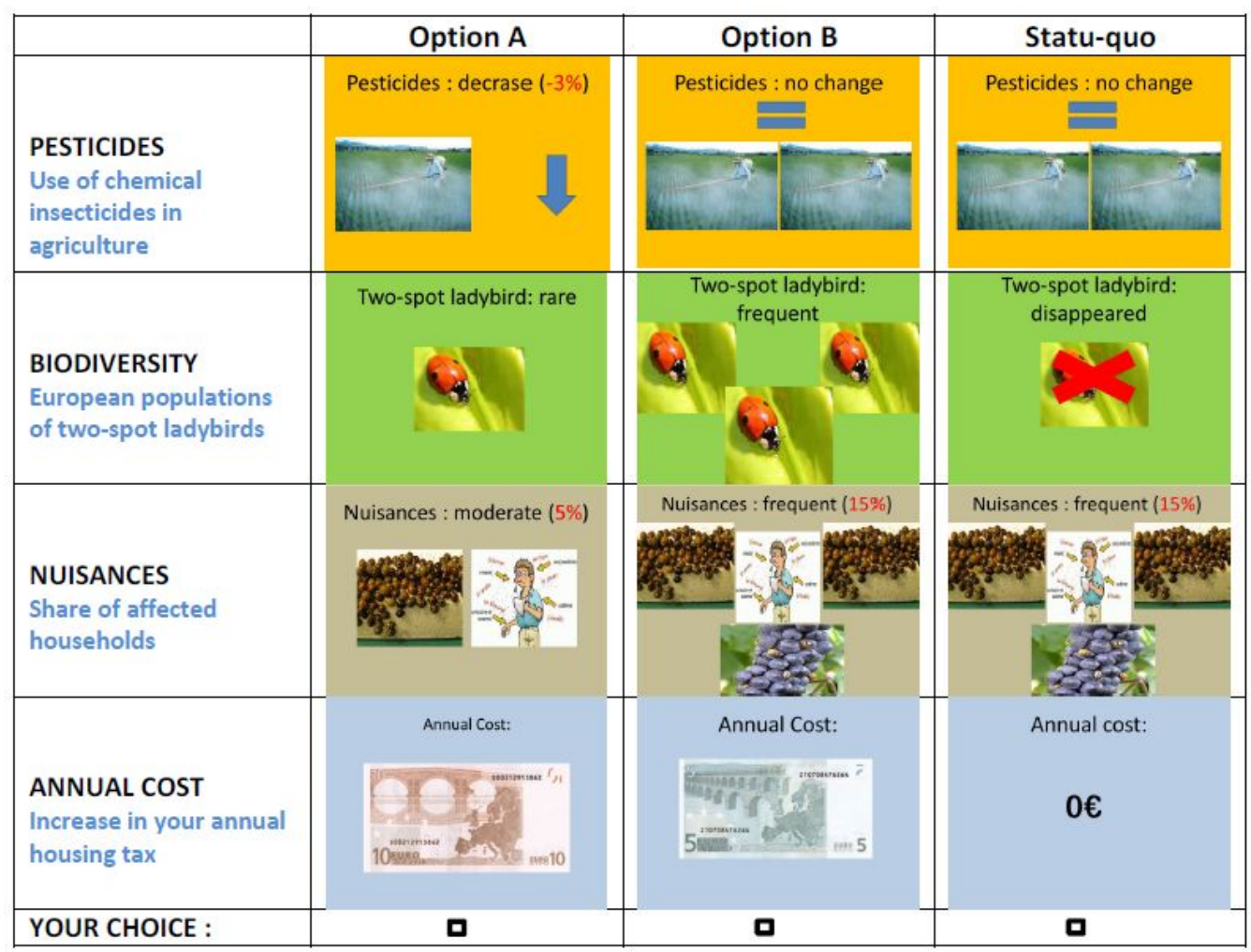

Figure 4: Example of a Choice Set

Then came the nine choice sets, composed of three options each. Participants were asked to carefully consider their current budget and expenditures in making their choices. The order of the choice sets was randomized so that declining attention issues would not systematically affect the same choice sets. In one of the choice sets, there was one dominated option (same monetary contribution but worse levels for all other attributes) which allowed to control for the respondent's consistency 8 . At the end of the nine choice sets, participants were asked whether they were satisfied with their answers and, in the case they were not, to explain why. Socio-demographic information on the respondent such as income level, gender, age and level of education were collected at the end of the questionnaire.

Among the respondents, 70 individuals (14\% of the sample) indicated they were not entirely satisfied with their answers. Most of them seemed to have understood the questions quite well and were simply frustrated by the trade-offs they had to make, for instance having to choose between less pesticides or more biodiversity. For this reason, we chose not to systematically exclude them from the sample. Note, moreover, that our econometric results are robust to their exclusion.

Moreover, 38 individuals ( $7.5 \%$ of the sample) selected the dominated option in one of the choice sets. This choice was consistent only if the person had a preference for an increase in

\footnotetext{
${ }^{8}$ This is proposed in the NGene design.
} 
pesticides. Therefore we checked in their responses along the other choice sets whether they were consistent with a positive willingness to pay for an increase in pesticides: they were not, so these 38 answers were excluded from our analysis. We also excluded one participant who had chosen the same option to all the choice sets, exhibiting inconsistent choices. The final sample used in the estimation therefore comprised the remaining 503-39=464 respondents.

\begin{tabular}{llll}
\hline & & France & Sample \\
\hline Age & & 44.86 & 44.77 \\
& $18-34$ & $26 \%$ & $25 \%$ \\
$35-49$ & $36 \%$ & $37 \%$ \\
$50+$ & $38 \%$ & $38 \%$
\end{tabular}

Socio-Professional Categories

$\begin{array}{rrl}\text { Upper } & 26 \% & 36 \% \\ \text { Lower } & 40 \% & 35 \% \\ \text { Non-working } & 21 \% & 23 \% \\ \text { Others } & 13 \% & 6 \%\end{array}$

Sex

Male $49 \% \quad 47 \%$

Female $51 \% \quad 53 \%$

Table 2: Comparison between our sample and the French population characteristics

\begin{tabular}{llll}
\hline Variable & Definition & mean & std.dev \\
\hline Sex & Gender of participant; Female =0 and Male =1 & 0.469 & 0.499 \\
Organic & 1 if purchase organic products regularly and 0 otherwise & 0.274 & 0.445 \\
Income & 1 if more than $€ 2219$ per month and 0 otherwise & 0.508 & 0.499 \\
Donation & 1 if make donations regularly and 0 otherwise & 0.103 & 0.304 \\
Rural & 1 if living in rural area and 0 otherwise & 0.469 & 0.499 \\
\hline
\end{tabular}

Table 3: Socio-demographic characteristics of the sample $(\mathrm{N}=464)$

Table 2 and Table 3 present the descriptive statistics for the final sample. The participants' ages range from 18 to 73 years, with an average of 45 years. The socio-demographic characteristics of the sample are very close to the French population's characteristics (see Table 2); our sample exhibits a slight over-representation of people in upper socio-professional categories, as it is usual in Internet and mail surveys (Olsen, 2009). 


\subsection{Econometric model}

The discrete choice experiment technique is an application of the characteristics theory of value (Lancaster, 1966), combined with random utility theory (McFadden, 1974). As suggested in the literature, we assume that the utility for each individual $i(i=1, \ldots, N)$ and each option $o$ $(o=1, \ldots, O)$ in each choice set $s(s=1, \ldots, S)$ is composed of a linear-in-parameters part, that depends on observable variables and an error term:

$$
U_{i o s}=\beta^{\prime} x_{i o s}+\gamma_{i}^{\prime} z_{i o s}+\varepsilon_{i o s}
$$

where $x_{i o s}$ and $z_{i o s}$ are the observed variables associated with option $o$ in choice set $s, \beta$ is the vector of fixed coefficients, $\gamma$ is a vector of random coefficients with mean zero and $\varepsilon_{i o s}$ is a vector of error terms. Option $o$ will be chosen over some other option $o^{\prime}$ if and only if $U_{i o s}>U_{i o^{\prime} s}$.

The econometric model depends on the assumption on the distribution of error terms. If the $\varepsilon_{i o s}$ are independent identically distributed (IID) type I extreme value, we have a random parameter logit (or mixed logit model) (Train, 2009). The standard logit is a special case of this model where $\gamma$ has a zero variance. The random parameter logit is a highly flexible model that can approximate any random utility model (McFadden and Train, 2000). It enables to avoid the three limitations of standard logit by allowing for random taste variation, unrestricted substitution patterns and correlation in unobserved factors over time (Train, 2009).

In the random parameter logit model, it is necessary to make an assumption regarding the distribution of each of the random coefficients. The choice is often limited by the difficulty of the model estimation and availability in econometric software. We assume here that the random parameters are normally distributed, which is the most easily applied distribution and which allows for both negative and positive preferences.

For a given value of $\gamma$, the conditional choice probability is a standard logit:

$$
L_{i o}(\gamma)=\frac{e^{\beta^{\prime} x_{i o}+\gamma_{i}^{\prime} z_{i o}}}{\sum_{o^{\prime} \in O} e^{\beta^{\prime} x_{i o^{\prime}}+\gamma_{i}^{\prime} z_{i o^{\prime}}}}
$$

and the unconditionnal choice probability, in the random parameter logit model, is the logit formula in equation (2) integrated over all values of $\gamma$ weighted by the density of $\gamma$ :

$$
P_{i o}=\int L_{i o}(\gamma) f(\gamma / \Omega) d \gamma
$$

where $f\left(L_{i o}(\gamma)\right)$ is the density of $\gamma$ and $\Omega$ is the fixed parameter of the distribution. The choice probability in equation (3) cannot be calculated exactly because the integral does not have a closed form in general. This integral is approximated through simulations. For a given value of the parameters $\Omega$, a value of $\gamma$ is drawn from its distribution. Using this draw, the 
logit formula in (2) is calculated. This process is repeated for many draws, and the mean of the resulting $L_{i o}(\gamma)$ is taken as the approximate choice probability yielding equation (4):

$$
S P_{i o}(\gamma)=\frac{1}{R} \sum_{r=1}^{R} L_{i o}\left(\gamma_{r}\right),
$$

where, $R$ is the number of draws of $\gamma$, and $S P$ is the simulated probability that an individual $i$ chooses option $o$.

In the analysis of the collected data, we estimate three types of models: the standard logit (SL), the conditional logit (CL) and the random parameter logit (RPL). The latter is the most flexible as it has the advantage of assuming that the alternatives are not independent and it takes into account unobserved heterogeneity as well as random taste variations among individuals (Train, 2009). In our model, the utility coefficients vary among individuals, but are constant among the choice situations for each individual. This reflects an underlying assumption of stable preference structures for all individuals (Train, 1999).

We use the estimated parameters to calculate the willingness to pay (WTP) associated with each attribute $k$ and each level $l$ as follows:

$$
W T P_{k l}=-\frac{\gamma_{k}^{l}}{\beta_{\text {cost }}}
$$

where $\gamma_{k}^{l}$ are the estimated parameters, which measure the variation of the utility associated with a variation of the attribute $k$ from the status quo level to the level $l$. $\beta_{\text {cost }}$ is the parameter associated with the cost attribute, i.e. the marginal utility of income which is assumed constant as is common in the literature (Hensher and Greene, 2003). WT $P_{k l}$ thus represents the willingness to pay to move from the status quo level of attribute $k$ to a level $l$.

In calculating a WTP, it is important that both parameters used in the calculation be statistically significant, otherwise no meaningful WTP measure can be established.

\section{Results and interpretation}

The estimation results of the three econometric models are shown in Table 4. The term cte $e_{S Q}$ refers to the alternative specific constant (ASC) associated with the status quo; it captures the utility associated with the status quo. As we have unlabeled options? we only include an ASC for the status quo alternative (Hoyos, 2010).

$\gamma_{\text {pesticide }}^{2}$ and $\gamma_{\text {pesticide }}^{3}$ are respectively the variation in utility due to a $3 \%$ increase and $3 \%$ decrease in pesticides compared to the status quo situation. $\gamma_{\text {biodiv }}^{2}$ and $\gamma_{\text {biodiv }}^{3}$ are respectively

\footnotetext{
${ }^{9}$ Each option in the choice sets does not necessarily correspond to a precise policy alternative which could be labeled, it is just a random combination of attributes' levels. As mentioned in subsection 3.1.1. the use of unlabeled options is common in the DCE literature.
} Agricultural Economics, 67 (3), 619-638. DOI : 10.1111/1477-9552.12160 
the variation in utility when increasing $A$. bipunctata's population from a "disappeared" level to a "rare" and "abundant" level. $\gamma_{\text {nuisance }}^{2}$ and $\gamma_{\text {nuisance }}^{3}$ are respectively the variation in utility when reducing the human nuisances due to the Asian ladybird from a "high" level to a "moderate" and a "insignificant" level. The parameters $\beta_{\text {sex }}^{S Q}, \beta_{\text {income }}^{S Q}, \beta_{\text {organic }}^{S Q}, \beta_{\text {donation }}^{S Q}$ and $\beta_{\text {rural }}^{S Q}$ are the coefficients associated with individual characteristics: sex, income, organic, donation and rural respectively (see Table 3). These individual characteristics are assumed to affect the variation of utility when moving away from the status quo.

The RPL model was estimated using logitm procedure of STATA 12. In the RPL model, all the parameters except the payment attribute and those associated with socio-demographic variables were specified to be normally distributed. The results of the RPL estimations are reported in the third and fourth columns of Table 4. They show that the standard deviations of the coefficients are significant, indicating that a RPL provides a significantly better representation of the choices than a SL, which assumes that coefficients are the same for all respondents. This indicates that the data supports choice specific unconditional unobserved heterogeneity for the considered attributes. Moreover, recent applications of the RPL model have shown that this model is superior to the CL model in terms of overall fit and welfare estimates (Lusk et al., 2003). For all these reasons, we focus our interpretations on the results of the random parameter logit model.

The parameters of all the attributes in the RPL model are statistically significant and have the expected signs. Unsurprisingly, the signs of $\beta_{\text {cost }}$ and $\gamma_{\text {pesticide }}^{2}$ are negative, meaning that an increase in costs or in the pesticides' use reduce the respondents' utility. The estimates of the parameters associated with the socio-demographic variables show that the gender, as well as the fact of living in rural areas, has no impact on the utilities of the respondents. Similarly, results show that giving donations for humanitarian or other reasons does not impact the utilities of respondents. However, frequent organic purchasers and respondents from higher income classes decrease their utility when staying in the status quo rather than moving away from this situation.

The choice experiment approach then allows us to estimate the WTP associated with each level of each attribute. Using equation (5), results of WTP are presented in Table 5. All the WTP estimates obtained with the RPL model are highly significant. They show that respondents are ready to pay on average $€ 10$ per year to increase European native ladybird population from the status quo level ("disappeared") to a level "abundant". Respondents seem also concerned by pesticides' use in agriculture as they are willing to pay on average $€ 3$ per year to decrease their level by $3 \%$ compared to their business-as-usual level. The WTP associated with an increased level of pesticides in agriculture are negative which means that the respondents need to receive on average $€ 6.5$ to compensate the utility loss associated with a $3 \%$ increase of pesticides. Regarding the human damages caused by the Asian ladybird, respondents have an Agricultural Economics, 67 (3), 619-638. DOI : 10.1111/1477-9552.12160 


\begin{tabular}{|c|c|c|c|c|}
\hline & \multirow{2}{*}{$\begin{array}{c}\text { SL } \\
\text { Param }\end{array}$} & \multirow{2}{*}{$\begin{array}{c}\text { CL } \\
\text { Param }\end{array}$} & \multicolumn{2}{|c|}{ RPL } \\
\hline & & & Param & $\mathrm{SD}$ \\
\hline \multirow[t]{2}{*}{ cte $_{S Q}$} & $-0.669^{* * *}$ & $0.737^{* * *}$ & -0.131 & $3.173^{* * *}$ \\
\hline & $(-9.27)$ & $(6.20)$ & $(0.37)$ & $(11.70)$ \\
\hline \multirow[t]{2}{*}{$\gamma_{\text {pesticide }}^{3}$} & $0.813^{* * *}$ & $1.006^{* * *}$ & $0.536^{* * *}$ & $0.541^{* *}$ \\
\hline & $(9.39)$ & (11.07) & $(5.08)$ & $(2.88)$ \\
\hline \multirow[t]{2}{*}{$\gamma_{\text {pesticide }}^{2}$} & $-0.695^{* * *}$ & $-0.263^{* *}$ & $-1.172^{* * *}$ & $1.806^{* * *}$ \\
\hline & $(-7.97)$ & $(-2.82)$ & $(-6.58)$ & (10.79) \\
\hline \multirow[t]{2}{*}{$\gamma_{\text {biodiv }}^{2}$} & $0.460^{* * *}$ & $0.917^{* * *}$ & $1.509^{* * *}$ & 0.140 \\
\hline & $(4.53)$ & $(8.63)$ & $(10.58)$ & $(0.81)$ \\
\hline \multirow{2}{*}{$\gamma_{\text {biodiv }}^{3}$} & $1.022^{* * *}$ & $1.324^{* * *}$ & $1.807^{* * *}$ & $0.734^{* * *}$ \\
\hline & (16.26) & (19.81) & (15.37) & $(5.20)$ \\
\hline \multirow[t]{2}{*}{$\gamma_{\text {nuisance }}^{2}$} & -0.138 & $0.391^{* * *}$ & $0.926^{* * *}$ & $0.512^{* * *}$ \\
\hline & $(-1.83)$ & $(4.62)$ & $(8.11)$ & $(3.92)$ \\
\hline \multirow{2}{*}{$\gamma_{\text {nuisance }}^{3}$} & $0.705^{* * *}$ & $1.028^{* * *}$ & $1.331^{* * *}$ & $1.019^{* * *}$ \\
\hline & (6.99) & $(9.77)$ & $(9.91)$ & $(8.74)$ \\
\hline \multirow[t]{2}{*}{$\beta_{\text {cost }}$} & $-0.178^{* * *}$ & $-0.124^{* * *}$ & $-0.180^{* * *}$ & \\
\hline & $(-22.50)$ & $(-14.60)$ & $(-13.92)$ & \\
\hline \multirow[t]{2}{*}{$\beta_{\text {sex }}^{S Q}$} & -0.0611 & -0.0813 & -0.0878 & \\
\hline & $(-0.81)$ & $(-0.92)$ & $(-0.20)$ & \\
\hline \multirow[t]{2}{*}{$\beta_{\text {organic }}^{S Q}$} & $-0.497^{* * *}$ & $-0.665^{* * *}$ & $-1.218^{* *}$ & \\
\hline & $(-5.38)$ & $(-6.29)$ & $(-2.92)$ & \\
\hline \multirow[t]{2}{*}{$\beta_{\text {donation }}^{S Q}$} & $-0.506^{* * *}$ & $-0.663^{* * *}$ & -0.750 & \\
\hline & $(-3.50)$ & $(-4.08)$ & $(-1.71)$ & \\
\hline \multirow[t]{2}{*}{$\beta_{\text {income }}^{S Q}$} & $-0.413^{* * *}$ & $-0.570^{* * *}$ & $-0.992^{*}$ & \\
\hline & $(-5.52)$ & $(-6.49)$ & $(-2.54)$ & \\
\hline \multirow[t]{2}{*}{$\beta_{\text {rural }}^{S Q}$} & $-0.278^{* * *}$ & $-0.384^{* * *}$ & -0.404 & \\
\hline & $(-3.69)$ & $(-4.36)$ & $(-1.19)$ & \\
\hline $\log L$ & -7407.72 & -6467.23 & -3422.87 & \\
\hline$N$ & 464 & 464 & 464 & \\
\hline$N \times S$ & 4176 & 4176 & 4176 & \\
\hline
\end{tabular}

Table 4: Estimation results

average WTP of respectively $€ 5$ and $€ 7$ per year to reduce these damages from their actual "high" (15\% of the population concerned) level to a "moderate" level (5\% of the population) 
and "insignificant" level (1\% of the population).

\begin{tabular}{lccc}
\hline & SL & CL & RPL \\
\hline Pesticides reduction $-3 \%$ & $4.576^{* * *}$ & $8.078^{* * *}$ & $2.976^{* * *}$ \\
& {$[3.505,5.648]$} & {$[6.151,10.00]$} & {$[1.659,4.293]$} \\
Pesticides increase $+3 \%$ & $-3.911^{* * *}$ & $-2.113^{* *}$ & $-6.505^{* * *}$ \\
& {$[-4.754,-3.068]$} & {$[-3.452,-0.775]$} & {$[-8.007,-5.003]$} \\
Rare biodiversity & $2.592^{* * *}$ & $7.369^{* * *}$ & $8.375^{* * *}$ \\
& {$[1.590,3.593]$} & {$[5.800,8.938]$} & {$[7.164,9.586]$} \\
Abundant biodiversity & $5.752^{* * *}$ & $10.63^{* * *}$ & $10.03^{* * *}$ \\
& {$[5.203,6.302]$} & {$[9.213,12.05]$} & {$[8.644,11.41]$} \\
Moderate nuisances & -0.775 & $3.137^{* * *}$ & $5.139^{* * *}$ \\
& {$[-1.643,0.0919]$} & {$[1.833,4.440]$} & {$[4.026,6.252]$} \\
Insignificant nuisances & $3.968^{* * *}$ & $8.260^{* * *}$ & $7.384^{* * *}$ \\
\hline 95\% confidence intervals in brackets. ${ }^{*} p<0.05,{ }^{* *} p<0.01,{ }^{* * *} p<0.001$ \\
The standard-deviation of WTP were calculated by the delta method.
\end{tabular}

Table 5: WTP estimates in $€$

As shown in our results, there is a significant willingness to pay to preserve the endangered two-spot ladybird, A. bipunctata. A household's willingness to pay to avoid the disappearance of this species in five years and reach an abundant population ranges from $€ 8.6$ to $€ 11.4$ per year. It is difficult to compare our results with the value obtained in the literature on DCEs valuing endangered species (ranging approximately from $€ 10$ to $€ 70$, depending on the species' type, whether the payment prevents extinction, on the extent of the variation of the population induced by the payment, whether it is a one time or annual payment, whether the concerned species is emblematic (Richardson and Loomis, 2009)). Most of these studies are dedicated to mammals, birds and fishes rather than insects, which explains the variation in the obtained values. Multiplying the obtained individual WTP by the number of households in France in 2010, we find that the total budget that could be dedicated to preserve A. bipunctata in France ranges from $€ 198$ million to $€ 266$ million per year.

The willingness to pay for a $3 \%$ pesticides reductions is $€ 3$ per year and per household. This estimate is not directly comparable to those obtained in the literature, due to differences in the 
analytical framework. Travisi and Nijkamp (2008) focus on the consequences of the variations in pesticides on several attributes, including biodiversity, while our motivation was to highlight some potential tradeoffs of biological control, requiring to consider chemical pesticides and biodiversity as two separate attributes. Chalak et al. (2008) found a willingness to pay of $£ 0.425$ a week (through higher expenditures in fruits and vegetables), i.e. around $€ 28$ a year for a $5 \%$ decrease in a wide class of chemical pesticides. The relative small willingness to pay we obtain for reducing pesticides might be due to the small extent of the reduction considered (3\% in five years may not seem substantial for a portion of the population 10 ) or to a lack of awareness on risks associated with pesticides 11 .

Furthermore, one may note the strong asymmetry between the willingness to pay for a reduction of pesticides and the willingness to accept for a same extent increase of pesticides. The total French population is willing to pay from $€ 45$ million to $€ 119$ million per year to decrease pesticides by $3 \%$ whereas it needs to receive between $€ 138$ million and $€ 222$ million to accept a $3 \%$ increase. This confirms a well-known result in the literature according to which a willingness to accept is higher than a willingness to pay for a same variation of the environmental quality.

Last, the WTPs for a reduction of human nuisances due to the Asian ladybird are significant. For instance, a household's willingness to pay to reduce these nuisances from a high level $(15 \%$ of the population) to an insignificant level ( $1 \%$ of the population) ranges from $€ 6.3$ to $€ 8.5$ per year. We thus find that the total budget that could be dedicated to solve $H$. axyridis's effects in housings and vineyards in France ranges from $€ 174$ million to $€ 235$ million per year.

Finally, the comparison of WTP-estimates in Table 5 provides some interesting insights on the tradeoffs in policy outcomes. It shows that the amount of money required for respondents to accept a small increase in pesticide use $(3 \%)$ is less - or comparable to - their willingness to pay for an improvement in the populations of the native two-spot ladybird. This is also the case for an important reduction of nuisances to humans and vineyards.

\section{Conclusion and discussion}

The objective of this paper was to provide an economic valuation of environmental and private characteristics affected by the use of the Asian ladybird as a biological control agent and by its

\footnotetext{
${ }^{10} \mathrm{As}$ a comparison, Chalak et al. (2008) explore the willingness to pay for a $5 \%, 10 \%, 20 \%$ and a $50 \%$ reduction of pesticides. However, we have chosen this level as a higher reduction would not be realistic as a consequence of the introduction of the Asian ladybird.

${ }^{11}$ In our will to stay as neutral as possible regarding the information delivered before the choice sets, we did not give a long description of the potential negative effects of chemical pesticides. Instead a short sentence mentioned potential effects on the environment and health. Detailing the impacts of pesticides on topics as sensitive as health and fertility might have distorted the results by shocking the population.
} Agricultural Economics, 67 (3), 619-638. DOI : 10.1111/1477-9552.12160 
invasion. A discrete choice experiment with efficient design was conducted among a representative sample of the French population. Three econometric models were estimated (standard logit, conditional logit, random paramter logit) yielding statistically significant estimates of the population's willingness to pay for various attributes linked to our topic : pesticides' use, local biodiversity and nuisances to humans and fruit cultures.

Our results show that all the attributes considered have a significant effect on the utility of respondents. In particular, regarding biodiversity, we highlight the existence value of the two-spot ladybird for which respondents are ready to pay $€ 10$ per year in average to increase the population from a "disappeared" level to an "abundant" level. Conversely, respondents would need to receive a payment of $€ 6.5$ per year in average to compensate the loss of welfare associated with a $3 \%$ increase of pesticides' use in agriculture.

Our quantitative analysis sheds some light on the questions raised in the introduction. Clearly, measures should be taken to address the negative consequences of the invasion, as they affect welfare significantly. Based on our evaluation of preferences, significant budgets - several hundred million euros in France - could be spent to solve the problems associated with this issue.

The tradeoff between the environmental benefits of biological control by Asian ladybirds (less chemical pesticides) and the environmental cost of the invasion on native species implies a balance between an environmental attribute with some private good characteristics (perceived effects of pesticides on one's individual health) and a pure public good (biodiversity). Here, free-riding effects - typical with pure public goods - do not seem to dominate as respondents are clearly taking both the private and public good into consideration. They are in average willing to accept a small increase in pesticides to avoid the disappearance of a native ladybirds species. This may be due to an irreversibility effect, making respondents reluctant to select an option where a species disappears (A. bipunctata), even when it is replaced by a close substitute $(H$. axyridis).

Our economic valuation gives support to van Lenteren et al. (2008)'s environmental risk assessment, stating that $H$. axyridis should probably not have been released in Northwest Europe : in France, the private and environmental costs of the invasion of $H$. axyridis appear to be significant in comparison to the environmental benefits of its use as a biological control agent. This result calls for the greatest caution in the future when considering the introduction of exotic species as biological control agents, while this importation process (classical biological control) remains common practice in many countries (Cock et al., 2010). Agricultural Economics, 67 (3), 619-638. DOI : 10.1111/1477-9552.12160 


\section{References}

Bartczak, A. and Meyerhoff, J. (2013). Valuing the chances of survival of two distinct eurasian lynx populations in poland : Do people want to keep the doors open? Journal of Environmental Management, 129(0):73 - 80.

Bekker-Grob, D., Esther, W., Hol, L., Donkers, B., Van Dam, L., Habbema, J. D. F., Van Leerdam, M. E., Kuipers, E. J., Essink-Bot, M.-L., and Steyerberg, E. W. (2010). Labeled versus unlabeled discrete choice experiments in health economics: an application to colorectal cancer screening. Value in Health, 13(2):315-323.

Brown, P., Adriaens, T., Bathon, H., Cuppen, J., Goldarazena, A., Hägg, T., Kenis, M., Klausnitzer, B., Kov, I., Loomans, A., et al. (2008). Harmonia axyridis in europe: spread and distribution of a non-native coccinellid. Springer Netherlands, pages 5-21.

Brown, P. M., Thomas, C. E., Lombaert, E., Jeffries, D. L., Estoup, A., and Handley, L.-J. L. (2011). The global spread of harmonia axyridis (coleoptera: Coccinellidae): distribution, dispersal and routes of invasion. BioControl, 56(4):623-641.

Brown, P. M. J., Ingels, B., Wheatley, A., Rhule, E. L., de Clercq, P., van Leeuwen, T., and Thomas, A. (2015). Intraguild predation by harmonia axyridis (coleoptera: Coccinellidae) on native insects in europe: molecular detection from field samples. Entomological Science, 18(1):130-133.

Chalak, A., Balcombe, K., Bailey, A., and Fraser, I. (2008). Pesticides, preference heterogeneity and environmental taxes. Journal of Agricultural Economics, 59(3):537-554.

Chevassus-au Louis, B., Salles, J.-M., and Pujol, J.-L. (2009). Approche economique de la biodiversite et des services liés aux écosystèmes. Technical report, Centre d'Analyse Stratégique.

Cock, M. J., van Lenteren, J. C., Brodeur, J., Barratt, B. I., Bigler, F., Bolckmans, K., Cônsoli, F. L., Haas, F., Mason, P. G., and Parra, J. R. P. (2010). Do new access and benefit sharing procedures under the convention on biological diversity threaten the future of biological control? BioControl, 55(2):199-218.

De Clercq, P., Mason, P. G., and Babendreier, D. (2011). Benefits and risks of exotic biological control agents. BioControl, 56(4):681-698.

Doherty, E., Campbell, D., Hynes, S., and van Rensburg, T. M. (2013). Examining labelling effects within discrete choice experiments: An application to recreational site choice. Journal of Environmental Management, 125(0):94 - 104. 
Ejbich, K. (2003). Producers in ontario and northern us bugged by bad odors in wines. The Wine spectator, 28(2):16.

Florax, R. J., Travisi, C. M., and Nijkamp, P. (2005). A meta-analysis of the willingness to pay for reductions in pesticide risk exposure. European Review of Agricultural Economics, $32(4): 441-467$.

Hanley, N., Czajkowski, M., Hanley-Nickolls, R., and Redpath, S. (2010). Economic values of species management options in human-wildlife conflicts: Hen harriers in scotland. Ecological Economics, 70(1):107-113.

Hanley, N., MacMillan, D., Patterson, I., and Wright, R. E. (2003). Economics and the design of nature conservation policy: a case study of wild goose conservation in scotland using choice experiments. Animal conservation, 6(2):123-129.

Hanley, N., Wright, R., and Koop, G. (2002). Modelling recreation demand using choice experiments: Climbing in scotland. Environmental and Resource Economics, 22(3):449-466.

Hensher, D. A. and Greene, W. H. (2003). The mixed logit model: the state of practice. Transportation, 30(2):133-176.

Hoyos, D. (2010). The state of the art of environmental valuation with discrete choice experiments. Ecological Economics, 69(8):1595-1603.

ISSG (2000). IUCN guidelines for the prevention of biodiversity loss caused by alien invasive species. Technical report, Approved by th 51st Meeting of IUCN Council, Gland Switzerland.

Kenis, M., Roy, H. E., Zindel, R., and Majerus, M. E. (2008). Current and potential management strategies against harmonia axyridis. Springer Netherlands, pages 235-252.

Koch, R. L. and Galvan, T. L. (2008). Bad side of a good beetle: the north american experience with harmonia axyridis. Springer Netherlands, pages 23-35.

Lancaster, K. (1966). A new approach to consumer theory. Journal of Political Economy, $74(2): 132-157$.

Louviere, J. J., Hensher, D. A., and Swait, J. D. (2000). Stated choice methods: analysis and applications. Cambridge University Press.

Lusk, J. L., Roosen, J., and Fox, J. A. (2003). Demand for beef from cattle administered growth hormones or fed genetically modified corn: a comparison of consumers in france, germany, the united kingdom, and the united states. American Journal of Agricultural Economics, $85(1): 16-29$. 
Majerus, M., Strawson, V., and Roy, H. (2006). The potential impacts of the arrival of the harlequin ladybird, harmonia axyridis (pallas)(coleoptera: Coccinellidae), in britain. Ecological Entomology, 31(3):207-215.

McFadden, D. (1974). Conditional logit analysis of qualitative choice behavior. chap. 2 in Frontiers in Econometrics. New York: Academic Press.

McFadden, D. and Train, K. (2000). Mixed mnl models for discrete response. Journal of applied Econometrics, 15(5):447-470.

McIntosh, C. R., Shogren, J. F., and Finnoff, D. C. (2010). Invasive species and delaying the inevitable: Valuation evidence from a national survey. Ecological Economics, 69(3):632 640.

Michaud, C., Llerena, D., and Joly, I. (2013). Willingness to pay for environmental attributes of non-food agricultural products: a real choice experiment. European Review of Agricultural Economics, 40(2):313-329.

Nunes, P. A. and van den Bergh, J. C. (2004). Can people value protection against invasive marine species? evidence from a joint tc-cv survey in the netherlands. Environmental and Resource Economics, 28(4):517-532.

Olsen, S. B. (2009). Choosing between internet and mail survey modes for choice experiment surveys considering non-market goods. Environmental and Resource Economics, 44(4):591610.

Pervez, A. and Omkar (2006). Ecology and biological control application of multicoloured asian ladybird, harmonia axyridi s: A review. Biocontrol Science and Technology, 16(2):111-128.

Pickering, G., Lin, J., Riesen, R., Reynolds, A., Brindle, I., and Soleas, G. (2004). Influence of harmonia axyridis on the sensory properties of white and red wine. American journal of oenology and viticulture, 55(2):153-159.

Rhule, E. L., Majerus, M. E., Jiggins, F. M., and Ware, R. L. (2010). Potential role of the sexually transmitted mite coccipolipus hippodamiae in controlling populations of the invasive ladybird harmonia axyridis. Biological Control, 53(2):243-247.

Richardson, L. and Loomis, J. (2009). The total economic value of threatened, endangered and rare species: An updated meta-analysis. Ecological Economics, 68(5):1535 - 1548.

Roy, H., Brown, P., and Majerus, M. (2006). Harmonia axyridis: A successful biocontrol agent or an invasive threat? Springer Netherlands, pages 295-309. 
Roy, H. E., Adriaens, T., Isaac, N. J., Kenis, M., Onkelinx, T., Martin, G. S., Brown, P. M., Hautier, L., Poland, R., Roy, D. B., et al. (2012). Invasive alien predator causes rapid declines of native european ladybirds. Diversity and distributions, 18(7):717-725.

Train, K. (1999). Mixed logit models for recreation demand. Valuing Recreation and the Environmentک̌, Edward Elgar, Northampton, MA.

Train, K. (2009). Discrete Choice Methods with Simulation, volume Second Edition. Cambridge University Press.

Travisi, C. M. and Nijkamp, P. (2008). Valuing environmental and health risk in agriculture: A choice experiment approach to pesticides in italy. Ecological Economics, 67(4):598 - 607.

van Lenteren, J. C. (2012). Internet Book of Biological Control. International Organization for Biological Control (IOBC).

van Lenteren, J. C., Loomans, A. J., Babendreier, D., and Bigler, F. (2008). Harmonia axyridis: an environmental risk assessment for northwest europe. BioControl, 53(1):37-54.

Wallmo, K. and Lew, D. K. (2011). Valuing improvements to threatened and endangered marine species: an application of stated preference choice experiments. Journal of environmental management, 92(7):1793-1801.

Whitehead, J. C. (2006). A practitioner's primer on the contingent valuation method. Handbook on contingent valuation, pages 66-91.

Yue, C. and Tong, C. (2009). Organic or local? investigating consumer preference for fresh produce using a choice experiment with real economic incentives. HortScience, 44(2):366-371. 